\title{
Overview of recent land cover changes in the biodiversity hotspots
}

Xiangping $\mathrm{Hu}$, Bo Huang, Francesca Verones, Otavio Cavalett, Francesco Cherubini*

Industrial Ecology Programme, Department of Energy and Process Engineering, Norwegian University of Science and Technology (NTNU), Trondheim, Norway

*Corresponding author. Phone: +4773598942; e-mail: francesco.cherubini@ntnu.no

This is a pre-submission, non-peer reviewed, preprint for self-archiving in EarthArXiv. The revised version of this manuscript has been provisionally accepted for publication by the scientific journal Frontiers in Ecology and the Environment (https://www.esa.org/frontiers-in-ecology-and-the-environment/), and it is currently In press. Once published by the journal, the link to the publication will be made available here. The final published version of the paper might have slightly different content than the present version. 


\begin{abstract}
Biodiversity hotspots are the most biologically rich, yet threatened, terrestrial regions. From 1992 to 2015, they underwent 148 Mha of land cover changes, including forest losses (56 Mha, of which 40 Mha caused by agricultural expansion), declines of shrubland or savannah (23 Mha), and urbanization (10 Mha). The three largest losses in forest areas occurred in Sundaland, Indo-Burma, and Mesoamerica, accounting for $11 \mathrm{Mha}, 6 \mathrm{Mha}$, and $5 \mathrm{Mha}$, respectively. This corresponds to a relative loss of $13 \%, 6 \%$, and $7 \%$, respectively, of the forest area originally present in 1992. Forest losses are also observed inside protected areas within the biodiversity hotspots. About 4.5 Mha of forests were lost between 2000 and 2015, and around 1 Mha of losses happened in the relatively recent past (between 2010 and 2015). Stricter and more effective land-based policies are needed to preserve threatened ecosystems and prevent risks of massive species extinction.
\end{abstract}

\title{
Introduction
}

Biodiversity decline is one of the most urgent challenges for our society (Tilman et al., 2017), and biodiversity hotspots were introduced to identify priority areas where major conservation efforts should be allocated (Figure 1a) (Brooks et al., 2002; Myers, 2003; Myers et al., 2000). To qualify as a biodiversity hotspot, an area must contain at least 1,500 species of vascular plants found nowhere else on Earth (endemic species), and have lost at least 70\% of its primary vegetation (Myers, 2003). Biodiversity hotspots cover about $16 \%$ of land globally and have lost around $85 \%$ of their original habitat, but they are the sole remaining habitats of about half of the Earth's plant species and more than one-third of the vertebrate species (Myers, 2003; Myers et al., 2000). Biodiversity hotspots thus host an enormous concentration of small-ranged species in places where most natural habitats have been cleared, and additional degradation can lead to an exceptionally large extinction spasm (Kobayashi et al., 2019; Myers, 2003; Tracewski et al., 2016).

Endemic species in biodiversity hotspots are highly vulnerable to land cover changes (LCCs) (Kobayashi et al., 2019; Sandel et al., 2011). LCCs increase extinction risks 
because they likely reduce habitat and facilitate anthropogenic interactions and disturbances, such as infrastructure, poaching or the introduction of alien species (Helmus et al., 2014). Furthermore, abrupt biodiversity declines are most likely to occur where landscape fragmentation is already high and additional habitat losses can trigger non-linear responses from threatened endemic species (Betts et al., 2017; Brooks et al., 2002), such as in the biodiversity hotspots. Deforestation is one of the main drivers that accelerates species extinction (Betts et al., 2017; Brooks et al., 2002; Tracewski et al., 2016), and remotely sensed datasets of changes in forest areas are frequently integrated with biodiversity databases to estimate species responses at different scales (Betts et al., 2017; Tracewski et al., 2016). However, the lack of a consistent global land cover dataset limited existing studies to focus on one type of land cover class at a time (usually forests) (Betts et al., 2017; Tracewski et al., 2016), or to use coarser databases with simplified differentiations in land cover types and trends (Kobayashi et al., 2019).

Recently, the European Space Agency (ESA) produced time-series (from 1992 to 2015) of high-resolution land cover maps (300 m) combining multiple remote sensing products and ground-truth observations (Defourny et al., 2017; Li et al., 2018). These maps were specifically developed to advance a more realistic representation of land cover dynamics in interdisciplinary studies, and provide an opportunity to refine biodiversity research to an unprecedented level of spatial and temporal accuracy. The aim of this study is to investigate the recent historical land cover changes that occurred in the biodiversity hotspots, and inside the protected areas within the biodiversity hotspots. LCCs are key indicators of potential risks for biodiversity. For example, expansion of agricultural land and reductions in forests and shrubland are typically associated with contractions in natural habitats for many species (Kobayashi et al., 2019; Tilman et al., 2017; Tracewski et al., 2016). Although previous studies individually investigated trends in land cover (mainly deforestation) for some of the hotspots, this analysis provides a first consistent overview of the land cover status in each hotspot at an unprecedented level of resolution. 


\section{Methods}

This analysis integrates the ESA land cover dataset with maps of biodiversity hotspots (Mittermeier et al., 2004; Myers, 2003), and protected areas therein (IUCN, 2019), to shed light on historical land transitions that occurred between 1992 and 2015.

The European Space Agency (ESA) Climate Change Initiative (CCI) land cover (LC) product is used to investigate the recent land transitions in the biodiversity hotspots. The ESA CCI-LC maps are provided at a spatial resolution of $300 \mathrm{~m}$ for a period of 24 years, from 1992 to 2015 (Defourny et al., 2017). These maps characterize the global surface using 37 land cover classes based on the United Nations Land Cover Classification System (UNLCCS), and were designed to overcome previous limitations and reduce uncertainty in the representation of land cover and LCCs (Defourny et al., 2017; Li et al., 2018). The dataset was produced after combination of the global daily surface reflectance of five different satellite observation systems, with the ambition to keep high levels of consistency over time. The dataset is increasingly used to assess patterns of landscape changes at different scales (Liu et al., 2018; Nowosad et al., 2018) and for land-climate interaction studies (Duveiller et al., 2018; Li et al., 2018). The accuracy of the CCI-LC maps was assessed at a global level against other datasets, and estimated to be generally larger than $70 \%$ for the different land cover classes (Defourny et al., 2017). The highest accuracy was found for cropland classes, forests, urban areas, bare areas, water bodies and perennial snow and ice. Mosaic classes, lichens and mosses showed the lowest accuracy. In order to facilitate the interpretation of the land transitions occurred in the biodiversity hotspots, we aggregated the 37 UNLCCS classes into the generic IPCC land classes, according to the specific cross-walking table provided by the ESA CCILC products (reproduced in Supplementary Table S7) (Defourny et al., 2017). The land cover transitions are more reliable when they involve changes between land cover types that belong to different overarching IPCC classes, than between UNLCCS classes that belong to the same IPCC class. For example, cropland-forest 
transitions have the highest accuracy, whereas gradual changes involving mosaic classes (e.g., shrubland-sparse vegetation transition) are less robust.

Land cover transitions within the biodiversity hotspots are produced by integrating the maps of the hotspots (Myers, 2003) with the global land cover dataset, and then the land cover differences between 1992 and 2015 within each hotspot are considered. The original resolution of $300 \mathrm{~m}$ for the maps is retained thanks to the use of an empowered server for the computations. Protected areas are those identified by the World Database on Protected Areas (WDPA), which is based on the definition of the IUCN/CBD for protected areas (i.e., a geographically defined area designated, regulated and managed to achieve specific conservation objectives) and is continuously updated by submissions from governments, land-owners and communities (IUCN, 2019). We select those within each biodiversity hotspot and investigate the changes in agricultural and forestland for our assessment period, and up to 2000 and 2010 to assess the most recent trends of LCCs within protected areas.

\section{Results}

\section{Land cover changes in the biodiversity hotspots}

Up to 148 Mha of gross land transitions occurred in all hotspots (Figure $1 \mathrm{~b}$ and Supplementary Tables S1-4). Most of the losses concerned forest cover (54 Mha, $37 \%$ ), followed by agriculture (39 Mha, 27\%), and shrubland or savannah (23 Mha, $15 \%)$. The main expansions are for agriculture (56 Mha, 38\%), forest (45 Mha, 30\%), human settlements (10 Mha, 7\%), and shrubland (10 Mha, 7\%). The net area changes showed an increase of agricultural land in the biodiversity hotspots of about 16 Mha, while forested areas declined by about 10 Mha. Land transitions typically involved from 5 to $10 \%$ of the total hotspot area (Figure 1c)

Different trends specific to each biodiversity hotspot emerged from our analysis (see Figure 2 and Supplementary Figures S1-5). Previous studies reported that further habitat losses from deforestation could trigger the most severe implications for 
biodiversity in hotspots \#27 Eastern Afromontane Arc, \#6 Coastal Forests of Eastern Africa, \#18 Philippines, \#34 Tropical Andes, \#15 Mesoamerica, \#21 Sundaland, \#10 Indo-Burma, \#13 Madagascar and \#22 Tumbes-Chocó-Magdalena (Brooks et al., 2002). Three of these hotspots, \#21 (Figure 2e), \#10 (Figure 2b), and \#15 (Figure 2d), show the three largest recent losses in forest areas, accounting for 11 Mha, 6 Mha, and 5 Mha, respectively. This corresponds to a relative loss of $13 \%, 6 \%$, and $7 \%$, respectively, of the forest area that was present in 1992. Other hotspots with high relative forest losses are in South Africa, i.e. \#14 Maputaland and \#25 Cape Floristic Region, where $22 \%$ and $18 \%$, respectively, of the forest cover in 1992 was lost. Forest losses are a major concern for the hotspots, where many vascular plants are endemic (Myers, 2003). The main driver of deforestation is usually expansion of agricultural land. Expansion of new forest areas ranged from 0.8 Mha in \#6 to 7 Mha in \#10, but the net forest changes are still negative for hotspots \#6, \#15,\#21, and \#34. In relative terms, the highest increases in forest areas are in hotspots \#16 Mountains of Central Asia (24\%), \#11 Irano-Anatolian (11\%), and \#1 Atlantic Forest (8\%), mainly due to new forest plantations. For example, in hotspot \#1 recent conservation measures focused on reforestation of agricultural land to contrast historical deforestation trends (Figure 2a) (Rezende et al., 2018). Although planting new forests can help to reduce extinction risks by increasing connectivity of vegetation remnants, biodiversity does not show immediate responses to forest expansion, meaning that young secondary forests do not mitigate biodiversity declines in the short-term (Betts et al., 2017; Lautenbach et al., 2017). Thus, increases in forest areas should neither be interpreted as a one-to-one compensation for forest losses, nor used as an argument to underestimate the biodiversity risks of deforestation.

A decline in shrubland by 6 Mha from expansion of agriculture is observed in hotspot \#26 Brazilian Cerrado, one of the richest tropical savannah regions with high levels of endemism (Figure $2 \mathrm{f}$ ). This loss corresponds to about $8 \%$ of the original vegetation cover in 1992. Large declines in shrubland (about 8.5 Mha, 29\%) are also found in \#10 (Figure 2b), mostly because of reforestation policies in the region (Tordoff et al., 2012). Loss of shrubland is much smaller in the other hotspots $(<1$ Mha). Context-specific information is needed for a more accurate interpretation of 
the transitions involving shrubland. For example, the shrubland-to-forest transition can indicate a development of early-stage trees in 1992 that were larger and denser in 2015, and the opposite transition (forest-to-shrubland), representing the largest gains in shrubland cover $(85 \%)$, can be a proxy of forest degradation.

Agriculture expansion usually happened at the expense of forests (68\%) and shrubland (15\%). The top three hotspots in terms of agriculture expansion are \#21 (11 Mha), \#26 (6.5 Mha) and \#10 (6 Mha). In relative terms, agricultural expansion is the largest in \#13 Madagascar (increased by 17\% relative to 1992, mostly replacing forests) (Figure 2c), whereas the major relative declines are in \#7 East Melenesian Islands (66\%) and \#32 New Zealand (36\%). Human settlements expanded by about 10 Mha, mostly at the expense of agricultural land (70\%). More than 1 Mha of human settlements occurred in \#10, \#12 Japan and \#30 Mediterranean Basin. In about half of the hotspots, areas of human settlements expanded by more than $100 \%$ relative to 1992.

\section{Land cover changes within protected areas}

Protected areas represent a key tool to safeguard biodiversity against increasing anthropogenic threats. However, areas currently under protection within the biodiversity hotspots were not exempted by LCCs (Supplementary Table S5). Between 1992 and 2015, about 16\% (average value) of total forest losses in the biodiversity hotspots occurred within protected areas. This corresponds to about 7.5 Mha, and it was mostly driven by agricultural expansion $(10 \%$ average value across all the hotspots). Most of the forest losses happened after 2000, i.e., the year that the concept of biodiversity hotspots gained larger international attention (Myers et al., 2000). About 4 Mha of forests within protected areas were lost in the period 20002015, about $52 \%$ on average across all the hotspots (Supplementary Table S6). Forest losses in protected areas are still occurring in the recent past, with an average of $15 \%$ of losses happening between 2010 and 2015 (corresponding to about 1 Mha). The biodiversity hotspots with the recent highest forest declines within protected areas 
are \#26 (131 kha, 28\% of the total losses in protected areas from 1992), \#21 (120 kha, 29\%), \#10 (108 kha, 9\%), and \#8 (90 kha, 13\%).

\section{Discussion}

This study provides an extensive quantitative analysis of the status of land covers and recent changes in each biodiversity hotspot. Declines in forest cover and shrubland are still significant in many hotspots. LCCs are an indicator commonly used to assess threats to biodiversity, but the specific implications for species abundance and extinction risks are highly dependent on the local context such as type of species, land uses involved, and patterns of land use changes, e.g., exacerbating landscape fragmentation or affecting pristine areas (Betts et al., 2017; Tracewski et al., 2016). The datasets produced in this analysis can be instrumental to future biodiversity research requiring high-resolution information to specifically investigate how recent trends affected habitats and species richness in the different hotspots.

Although they have experienced a severe loss of primary vegetation, biodiversity hotspots still host many endemic species. This study shows that halting deforestation in the biodiversity hotspots remains a priority. Even moderate additional habitat destruction can cause time-delayed but deterministic extinction in remnant patches, and the more fragmented a habitat already is, the greater the number of extinctions caused by added destruction will be (Tilman et al., 1994; Wearn et al., 2012). Pressure on biodiversity from LCCs is likely to increase in the future due to increasing demands for food, feed, and energy from population growth and stringent climate stabilization objectives that require land for production of renewable energy and negative emissions (e.g., afforestation or bioenergy crops) (Popp et al., 2017). These drivers can further exacerbate the threats to vulnerable endemic species, and cross-boundary land use policies and context-specific conservation strategies are needed to mitigate potential risks. 
Protected areas are a key strategy for biodiversity conservation and are promoted through multiple international conventions and agreements. Although there are different levels of management allowed within protected areas, the scale of the observed changes therein raises concerns about the safeguarding of endemic and threatened species and calls for improving the effectiveness of existing conservation measures. There is evidence that financial support for protected areas has reduced and this had direct implications in habitat degradation and extinction risks (Coad et al., 2019; Jones et al., 2018). Less than one quarter of the global protected areas has adequate resources in terms of both staffing and budget (Coad et al., 2019), and our analysis finds that about 1 Mha of forest losses happened in the relatively recent past within protected areas (between 2010 and 2015), with irreversible risks for thousands of species. Together with further expanding protected areas to those ecosystems that are threatened, a shift in the degree of effectiveness and quality of conservation measures in existing protected areas is required in light of the still ongoing land cover changes. However, many biodiversity hotspots are in developing countries with substantial poverty, where resources for conservation measures are usually scarce and land use regulations difficult to implement. The success of conservation activities crucially depends on making conservation a relevant component of poverty alleviation (Fisher and Christopher, 2007). In the absence of such concerted international efforts we risk losing irreplaceable and vulnerable species. 
a

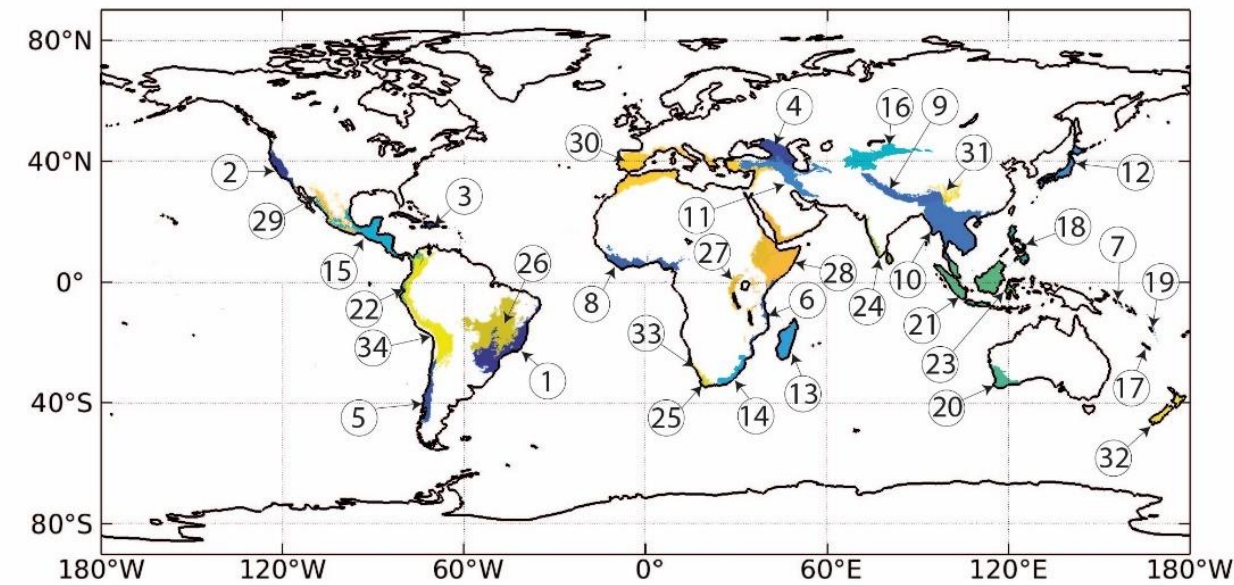

b

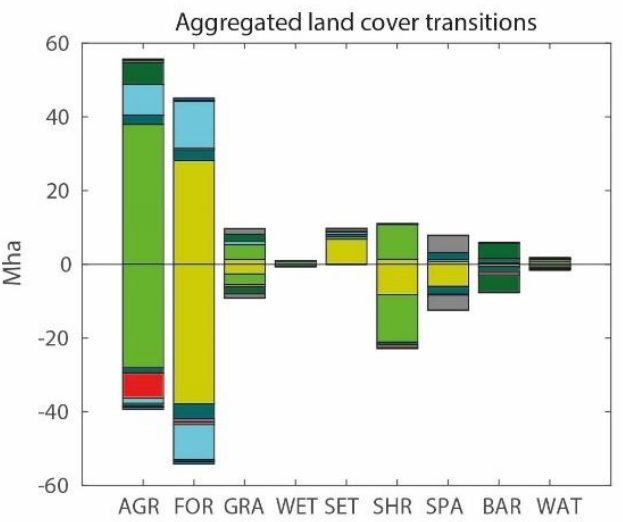

$\begin{array}{ll}1 \text { Atlantic Forest } & 18 \text { Philippines } \\ \text { 2 California Floristic Province } & 19 \text { Polynesia-Micronesia } \\ 3 \text { Caribbean Islands } & 20 \text { Southwest Australia } \\ 4 \text { Caucasus } & 21 \text { Sundaland } \\ 5 \text { Chilean Winter Rainfall-Valdivian Forests } 22 \text { Tumbes-Chocó-Magdalena } \\ 6 \text { Coastal Forests of Eastern Africa } & 23 \text { Wallacea } \\ 7 \text { East Melanesian Islands } & 24 \text { Western Ghats and Sri Lanka } \\ 8 \text { Guinean Forests of West Africa } & 25 \text { Cape Floristic Region } \\ 9 \text { Eastern Himalaya } & 26 \text { Cerrado } \\ \text { 10 Indo-Burma } & 27 \text { Eastern Afromontane } \\ \text { 11 Irano-Anatolian } & 28 \text { Horn of Africa } \\ \text { 12 Japan } & 29 \text { Madrean pine-oak woodlands } \\ \text { 13 Madagascar } & 30 \text { Mediterranean Basin } \\ \text { 14 Maputaland-Pondoland-Albany } & 31 \text { Mountains of Southwest China } \\ \text { 15 Mesoamerica } & 32 \text { New Zealand } \\ \text { 16 Mountains of Central Asia } & 33 \text { Succulent Karoo } \\ \text { 17 New Caledonia } & 34 \text { Tropical Andes }\end{array}$

$\square$ AGR: Agriculture (16.35) $\square$ FOR: Forest (-9.08) $\square$ GRA: Grassland (0.53)

- $\square$ WET: Wetland (0.32) Settlement (9.80) $\square$ SHR: Shrubland (-11.80) - 5 SPA: Sparse vegetation $(-4.60) \square$ BAR: Bare area $(-1.74)$ WAT: Water (0.22)

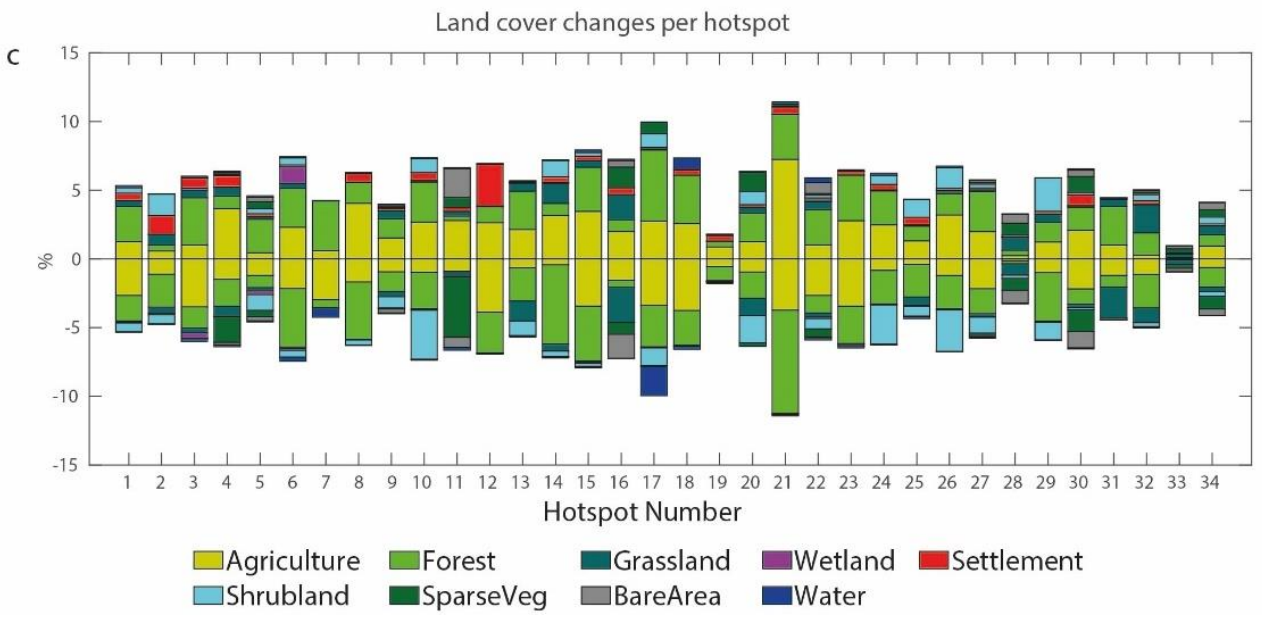

Figure 1 Biodiversity hotspots and major land cover transitions. Location of the biodiversity hotspots in the world (a); aggregated land cover transitions across all hotspot areas between 1992 and 2015 (b); breakdown of the relative change in each individual land cover type per hotspot, as a percentage of the total hotspot area (c). Positive values indicate an expansion of the respective land cover, negative values a contraction. Legend in (b) also shows the net area change per land cover class. 

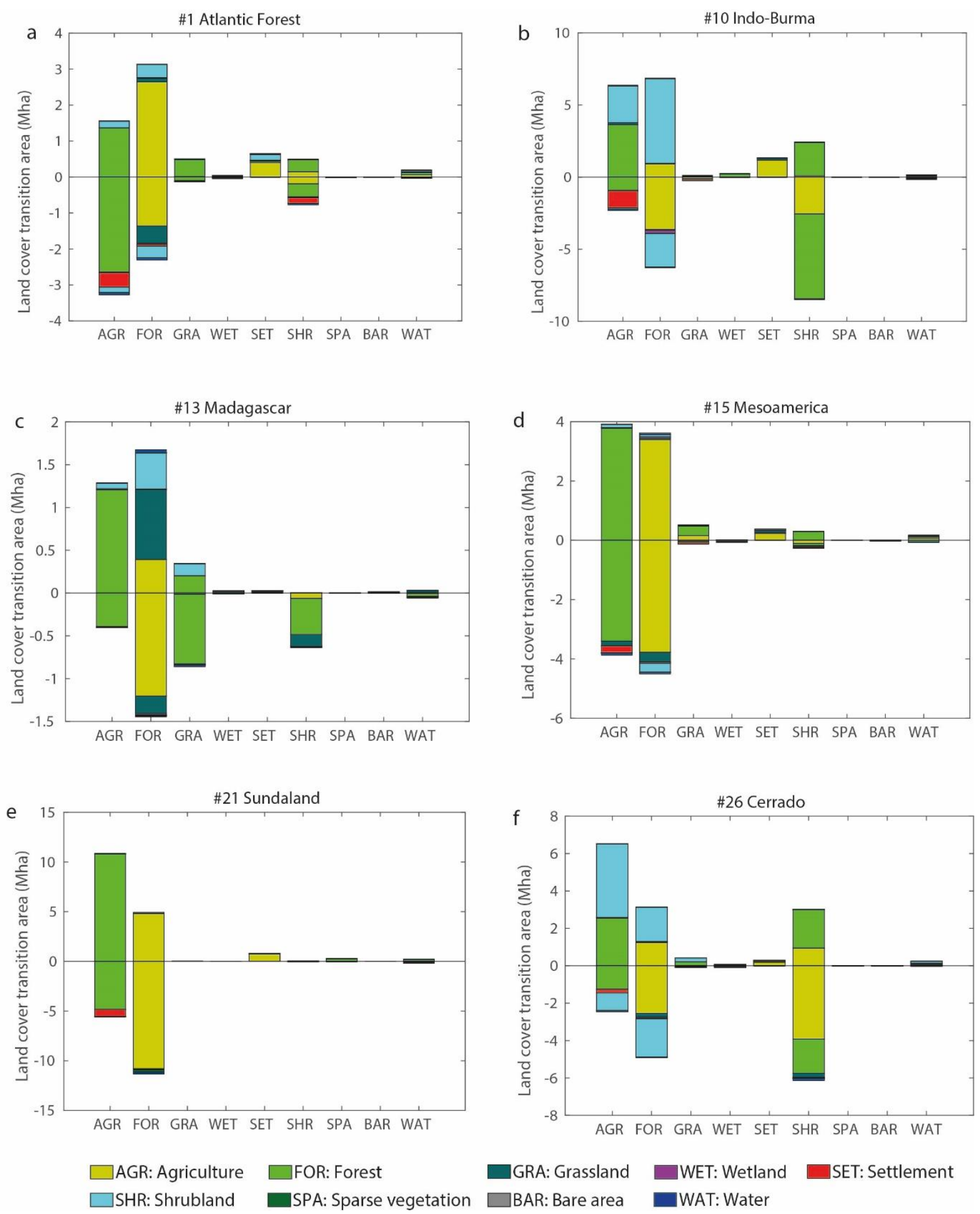

Figure 2 Recent historical land cover changes in selected biodiversity hotspots between 1992 and 2015. Per each land class, the transitions to other land classes is explained by the color code in the legend. Positive values indicate an expansion of the respective land cover, negative values a contraction. Land transitions for the remaining hotspots are shown in Supplementary Figures S1-5. 


\section{References}

Betts, M.G., Wolf, C., Ripple, W.J., Phalan, B., Millers, K.A., Duarte, A., Butchart, S.H.M., Levi, T. (2017) Global forest loss disproportionately erodes biodiversity in intact landscapes. Nature 547, 441.

Brooks, T.M., Mittermeier, R.A., Mittermeier, C.G., Da Fonseca, G.A.B., Rylands, A.B., Konstant, W.R., Flick, P., Pilgrim, J., Oldfield, S., Magin, G., Hilton-Taylor, C. (2002) Habitat Loss and Extinction in the Hotspots of Biodiversity. 16, 909-923.

Coad, L., Watson, J.E., Geldmann, J., Burgess, N.D., Leverington, F., Hockings, M., Knights, K., Di Marco, M. (2019) Widespread shortfalls in protected area resourcing undermine efforts to conserve biodiversity. Frontiers in Ecology and the Environment 17, 259-264.

Defourny, P., S. Bontemps, C. Lamarche, C. Brockmann, M. Boettcher, J. Wevers, ., G.K., (2017) Land Cover CCI: Product User Guide Version 2.0, Avaliable at: http://maps.elie.ucl.ac.be/CCI/viewer/.

Duveiller, G., Hooker, J., Cescatti, A. (2018) The mark of vegetation change on Earth's surface energy balance. Nature Communications 9, 679 .

Fisher, B., Christopher, T. (2007) Poverty and biodiversity: Measuring the overlap of human poverty and the biodiversity hotspots. Ecological Economics 62, 93-101.

Helmus, M.R., Mahler, D.L., Losos, J.B. (2014) Island biogeography of the Anthropocene. Nature 513, 543.

IUCN (2019) Protected Planet: The World Database on Protected Areas (WDPA), UNEPWCMC and IUCN. Cambridge, UK. Available at: www.protectedplanet.net.

Jones, K.R., Venter, O., Fuller, R.A., Allan, J.R., Maxwell, S.L., Negret, P.J., Watson, J.E.M. (2018) One-third of global protected land is under intense human pressure. Science 360, 788791.

Kobayashi, Y., Okada, K.-i., Mori, A.S. (2019) Reconsidering biodiversity hotspots based on the rate of historical land-use change. Biological Conservation 233, 268-275.

Lautenbach, S., Jungandreas, A., Blanke, J., Lehsten, V., Mühlner, S., Kühn, I., Volk, M. (2017) Trade-offs between plant species richness and carbon storage in the context of afforestation - Examples from afforestation scenarios in the Mulde Basin, Germany. Ecological Indicators 73, 139-155.

Li, W., MacBean, N., Ciais, P., Defourny, P., Lamarche, C., Bontemps, S., Houghton, R.A., Peng, S. (2018) Gross and net land cover changes in the main plant functional types derived from the annual ESA CCI land cover maps (1992-2015). Earth Syst. Sci. Data 10, 219-234.

Liu, X., Yu, L., Si, Y., Zhang, C., Lu, H., Yu, C., Gong, P. (2018) Identifying patterns and hotspots of global land cover transitions using the ESA CCI Land Cover dataset. Remote Sensing Letters 9, 972-981. 
Mittermeier, R.A., Robles Gil, P., Hoffmann, M., Pilgrim, J., Brooks, T., Mittermeier, C.G., da Fonseca, G.A.B. (2004) Hotspots Revisited: Earthís Biologically Richest and Most Endangered Ecoregions Mexico City, Mexico.

Myers, N. (2003) Biodiversity Hotspots Revisited. BioScience 53, 916-917.

Myers, N., Mittermeier, R.A., Mittermeier, C.G., da Fonseca, G.A.B., Kent, J. (2000)

Biodiversity hotspots for conservation priorities. Nature 403, 853.

Nowosad, J., Stepinski, T.F., Netzel, P. (2018) Global assessment and mapping of changes in mesoscale landscapes: 1992-2015. International Journal of Applied Earth Observation and Geoinformation.

Popp, A., Calvin, K., Fujimori, S., Havlik, P., Humpenöder, F., Stehfest, E., Bodirsky, B.L., Dietrich, J.P., Doelmann, J.C., Gusti, M., Hasegawa, T., Kyle, P., Obersteiner, M., Tabeau, A., Takahashi, K., Valin, H., Waldhoff, S., Weindl, I., Wise, M., Kriegler, E., Lotze-Campen, H., Fricko, O., Riahi, K., Vuuren, D.P.v. (2017) Land-use futures in the shared socio-economic pathways. Global Environmental Change 42, 331-345.

Rezende, C.L., Scarano, F.R., Assad, E.D., Joly, C.A., Metzger, J.P., Strassburg, B.B.N., Tabarelli, M., Fonseca, G.A., Mittermeier, R.A. (2018) From hotspot to hopespot: An opportunity for the Brazilian Atlantic Forest. Perspectives in Ecology and Conservation 16, 208-214.

Sandel, B., Arge, L., Dalsgaard, B., Davies, R.G., Gaston, K.J., Sutherland, W.J., Svenning, J.C. (2011) The Influence of Late Quaternary Climate-Change Velocity on Species Endemism. 334, 660-664.

Tilman, D., Clark, M., Williams, D.R., Kimmel, K., Polasky, S., Packer, C. (2017) Future threats to biodiversity and pathways to their prevention. Nature 546, 73.

Tilman, D., May, R.M., Lehman, C.L., Nowak, M.A. (1994) Habitat destruction and the extinction debt. Nature 371, 65-66.

Tordoff, A., Baltzer, M., Fellowes, J., Pilgrim, J., Langhammer, P. (2012) Key Biodiversity Areas in the Indo-Burma Hotspot: Process, Progress and Future Directions. Journal of Threatened Taxa 4(8), 2779-2787.

Tracewski, Ł., Butchart, S.H.M., Di Marco, M., Ficetola, G.F., Rondinini, C., Symes, A., Wheatley, H., Beresford, A.E., Buchanan, G.M. (2016) Toward quantification of the impact of 21st-century deforestation on the extinction risk of terrestrial vertebrates. 30, 1070-1079.

Wearn, O.R., Reuman, D.C., Ewers, R.M. (2012) Extinction Debt and Windows of Conservation Opportunity in the Brazilian Amazon. 337, 228-232. 